\section{Development of Technologies on Innovative-Simplified Nuclear Power Plant using High-Efficiency Steam Injectors \\ - System Outline and Endurance Test of Low-Pressure Steam Injectors -*}

\author{
Shuichi OHMORI ${ }^{* *}$ Tadashi NARABAYASHI ${ }^{* * * * * * * *}$ Michitsugu MORI $^{* *}$ \\ Chikako IWAKI $^{* * *}$ Yutaka ASANUMA ${ }^{* * *}$ and Shoji GOTO ${ }^{* *}$ \\ **Research \&Development Center, The Tokyo Electric Power Company, Incorporated, \\ 4-1, Egasaki-cho, Tsurumi-ku, Yokohama, 230-8510, Japan \\ E-mail: ohmori.shuichi@tepco.co.jp \\ ***Power Systems Company, Toshiba Corporation, \\ 8, Shinsugita-cho, Isogo-ku, Yokohama, 235-8523, Japan \\ ****Present Address, Hokkaido University,
}

Kita 13, Nishi 8, Kita-ku, Sapporo, 060-8628, Japan

\begin{abstract}
A Steam Injector (SI) is a simple, compact and passive pump and also acts as a high-performance direct-contact heater. This provides SI with capability to serve also as a direct-contact feed-water heater that heats up feed-water by using extracted steam from turbine. Our technology development aims to significantly simplify equipment and reduce physical quantities by applying "High-Efficiency SI", which are applicable to a wide range of operation regimes beyond the performance and applicable range of existing SIs and enables unprecedented multistage and parallel operation, to the low-pressure feed-water heaters and Emergency Core Cooling System of nuclear power plants, as well as achieve high inherent safety to prevent severe accidents by keeping the core covered with water (a Severe Accident-Free Concept). This paper describes the results of the endurance and performance tests of low-pressure SIs for feed-water heaters with Jet-deaerator and core injection system.
\end{abstract}

Key words: Steam Injector, Multi-Stage SIs, Jet-Deaerator, Innovative-Simplified Nuclear Power Plant, Simplified Feed-Water Heating System, Passive Core Injection System, Endurance Test

\section{Introduction}

Nuclear power plants have a number of advantages in that "nuclear power plants are environmentally acceptable as they do not produce carbon dioxide, and fuel loaded in a reactor core has a stockpiling effect to be advantageous in terms of Japan's energy security." On the other side of the coin, however, the cost of constructing new nuclear power plants is increasing and nuclear power plants are facing competition from advanced-combined-cycle thermal power plants in terms of power costs. Furthermore, when it comes to a fourth-generation nuclear reactor that is now becoming the mainstay reactor technology in Europe and the United States, there is a growing call for the incorporation of capability to deal with severe accidents in a reactor design. For these reasons, nuclear power plants are 
becoming less attractive in terms of overall costs including back-end expenses.

Based on the High-Efficiency Steam Injector (SI) technology that has been developed to achieve high performance and extend an application range ${ }^{(1) \sim(5)}$, the project has for its objective to simplify nuclear power plants, substitute SIs for feed-water heaters and Emergency Core Cooling System (ECCS), thereby to substantially simplify systems and components, achieve material reductions, and high inherent safety to save the core from severe accidents by keeping the core covered with water (a Severe Accident-Free Concept), thus enhancing the reliability and international price competitiveness of Japanese nuclear power plants. ${ }^{(6)}$

SI is a passive jet pump that has no movable part and drives feed-water by supersonic jet. The two types of SI are existing as shown in Fig.1 (a) and (b) ${ }^{(7),(8)}$. When water is injected from the water jet nozzle at the axial center in the case of Fig.1 (b) and steam is supplied to the annular steam nozzle composed of the outside of the water jet nozzle and the mixing nozzle inlet, the steam becomes a supersonic flow in the mixing nozzle and accelerates the water jet, producing a high-speed water flow at the throat. In the after-throat process, steam condensation is completed and the flow changes into a single-phase water flow, which is decelerated by a diffuser, with its pressure rising to a high level in accordance with Bernoulli's principle.

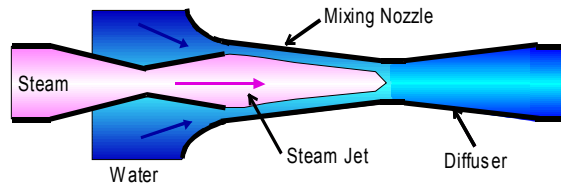

(a) Central Steam Jet type SI

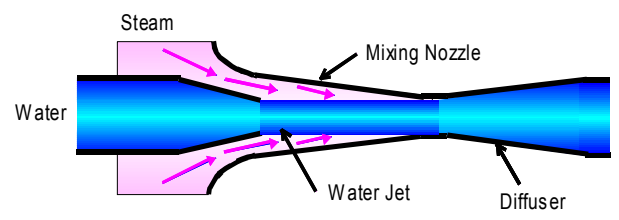

(b) Central Water Jet type SI

Fig. 1 Two types of Steam Injector (SI)

In addition to its function as a pump, the SI works as a heat exchanger through direct contact between steam and water. This provides the SI with capability to serve also as a direct-contact feed-water heater that heats up feed-water by using extracted steam from the turbine. As it is compact equipment, the SI is expected to bring about great simplification and materials-saving effects, while its simple structure ensures high reliability of its operation, thereby greatly contributing to the simplification of the power plant. ${ }^{(6)}$

\section{Innovative-Simplified Nuclear Power Plant}

The Innovative-Simplified Nuclear Power Plant as shown in Fig.2, consists of a Simplified Feed-water Heating System, a Passive Core Coolant Injection System and a Passive Containment Cooling System. ${ }^{(6),(9),(10)}$

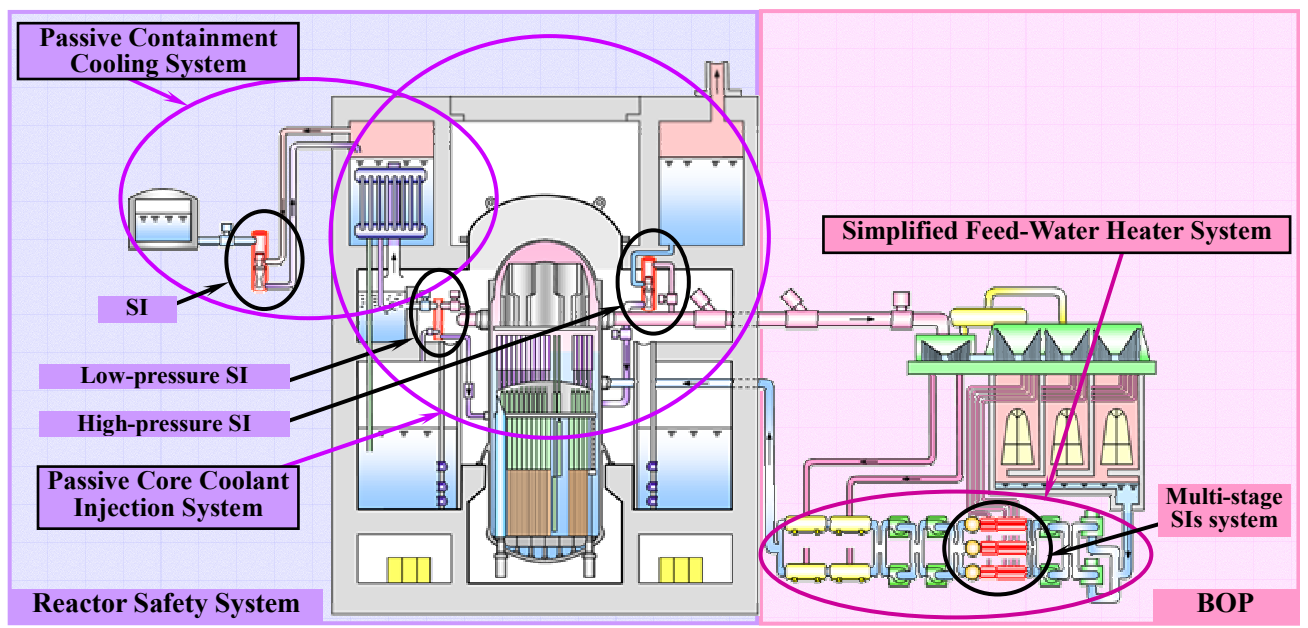

Fig. 2 Basic Concept of Innovative-Simplified Nuclear Power Plant 


\subsection{Simplified Feed-water Heating System}

The high-performance SI system with multistage parallel operation ${ }^{(1)-(5)}$, having been developed in the present project, outperforms conventional SIs, because of its wider operating and application ranges from higher through lower steam pressures, compared with conventional SIs, which attains higher discharge pressure than the supply steam pressure. We have been developing the multistage SI system as shown in Fig.3, composed of the first-stage, second-stage, third-stage, and final-stage SIs with the Jet-deaerator. ${ }^{(6)}$

Tokyo Electric Power Company (TEPCO) and Toshiba have promoted the joint research project designed to develop SI systems. As a result of the introduction of the advanced computational fluid dynamics (CFD) technology, the parallel and multistage high-performance SI, necessary for achieving a large-capacity design, a requirement of nuclear power plants, has successfully been developed, where SI technologies have taken great strides in its progress. Figure 4 shows the advanced boiling water reactor (ABWR) and its feed-water heating system, which has a total of 12 four-stage, three-series low-pressure feed-water heaters. The feed-water heating system of ABWR, shown in Fig.5 (a), can be simplified by the parallel and multistage SI system as shown in Fig.5 (b). The low-pressure feed-water heaters of ABWR, which are placed inside the huge condenser as necked heaters as shown in Fig.6, for the case of which the turbine building height can be reduced by $\sim 3.5 \mathrm{~m}$ with the simplified feed-water heating system using the multistage SIs, as demonstrated by layout design in Fig.7. The comparison exhibited the volume and weight reduction between ABWR and the simplified plant by SI system as shown in Fig.8, applying the multistage parallel-operation SI system for the feed-water heating system. The weight and volume of the feed-water heating system of the simplified plant can be reduced by around one-third, compared with those of ABWR. ${ }^{(6)}$

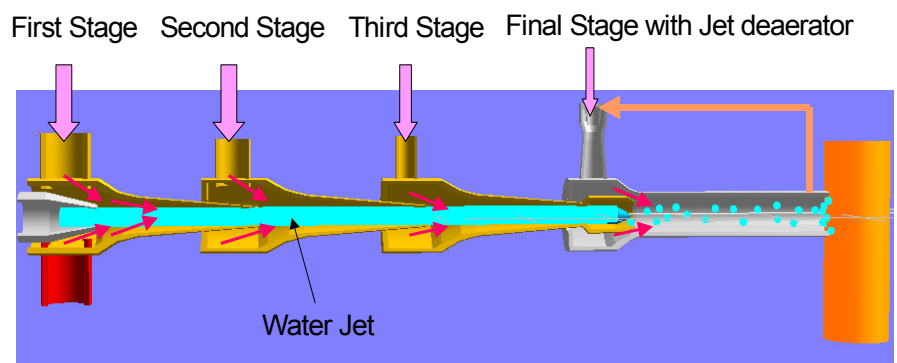

Fig.3 Four-stage SI system with Jet-deaerator

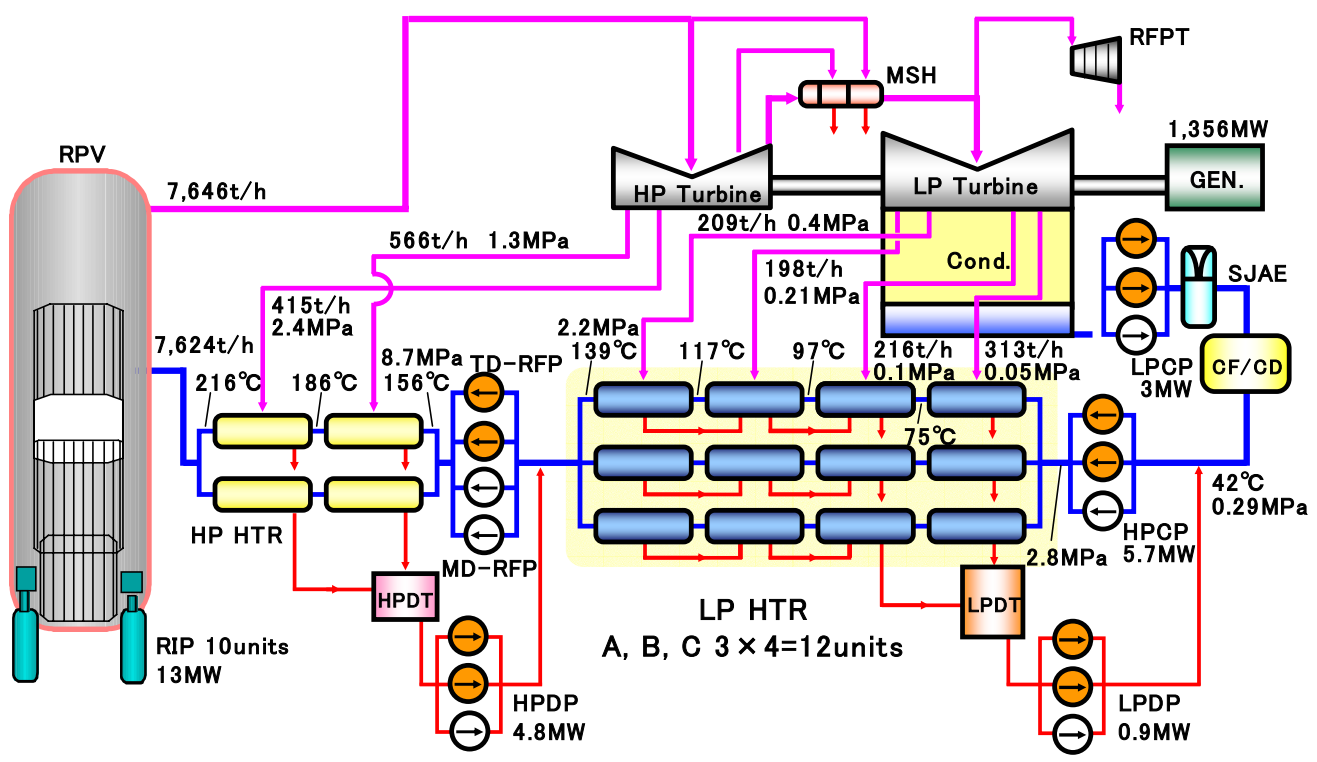

Fig.4 ABWR and feed-water heating system 


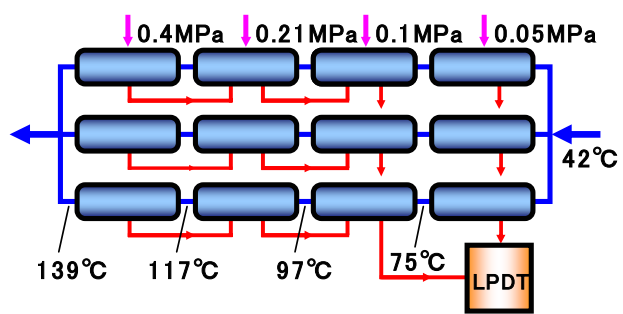

(a) Four-stage, Three-series low-pressure feed-water heaters of ABWR

Fig.5 Replacement of ABWR feed-water heaters by the multi-stage SI system

In addition, the results of the heat balance analysis, the plant efficiency of this Innovated-Simplified Nuclear Power Plant with simplified feed-water heating system will improve compared with the current BWR with conventional feed-water heating system. ${ }^{(11)}$

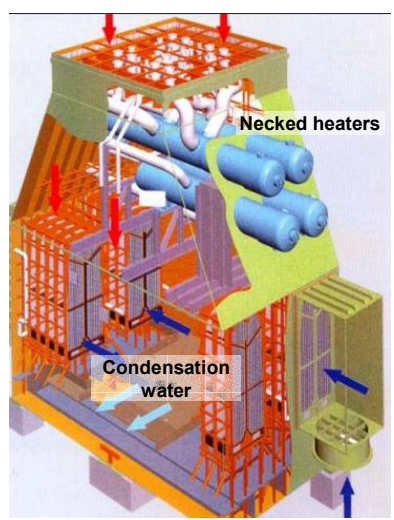

Fig. 6 Low-pressure necked feed-water heaters of ABWR

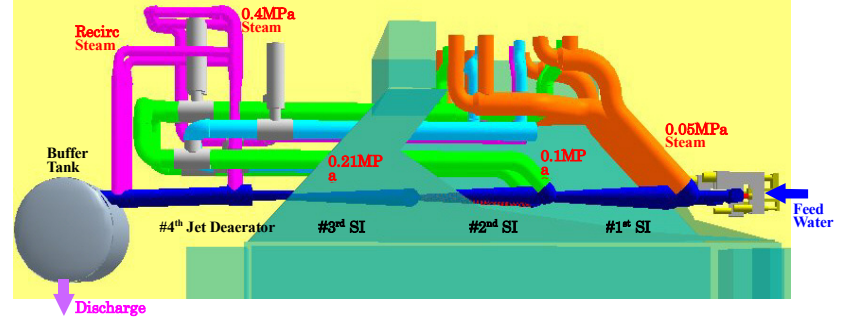

Fig. 7 Layout of simplified feed-water heating system by Multi-stage SIs

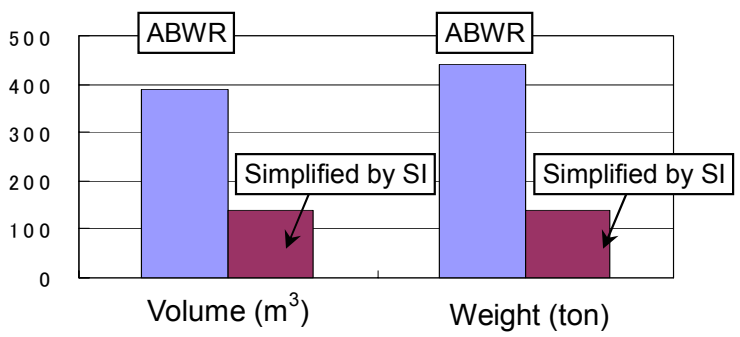

Fig.8 Comparison of volume and weight reduction of feed-water heating system

\subsection{Passive Core Coolant Injection System}

The Passive Core Coolant Injection System driven by High-Efficiency SIs is a system that, in an accident such as a LOCA (loss of coolant accident), attains discharge pressure higher than the supply steam pressure to inject water into the reactor by operating the SIs using the pool water in the containment vessel as the source of water supply and the steam contained in the reactor as the source of pressurization energy as shown in Fig.9. The SIs, passive equipment, is used to replace large rotating machines (active equipment) such as pumps and motors, eliminating the failure probabilities of such active equipment. ${ }^{(9),(10)}$

In a SI-driven Core Coolant Passive Injection System, redundancy will be provided to ensure that the water and steam supply valves to the SIs open reliably, and when the valves open, the SIs will automatically start to inject water into the core to keep the core covered with water. Thus, the SI enables the development of systems with high inherent safety to save the core from severe accidents. (a Severe Accident-Free Concept) ${ }^{(9),(10)}$

A wide range of operation pressures from about $8 \mathrm{MPa}$ to as low as about $0.1 \mathrm{MPa}$ can be covered with a system consisting of a combination of multiple SIs, for example, using a central steam jet-type SI as the High-Pressure Core Injection System and a central water jet-type SI as the Low-Pressure Core Injection System. ${ }^{(9),(10)}$ 


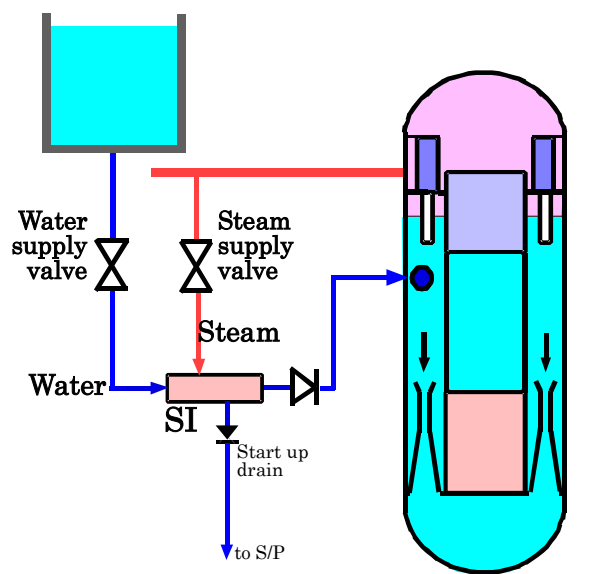

Fig. 9 Passive Core Coolant Injection System using SI

\subsection{Passive Containment Cooling System}

Passive Containment Cooling System (PCCS) was studied as a simple and passive safety system for core cooling and decay heat removal after a LOCA by utilizing natural forces. PCCS serves as long term cooling function to remove decay heat and to suppress the PCV pressure below the design pressure ${ }^{(12)}$. An SI driven PCCS water refill system was investigated as a simplified and innovative nuclear safety system ${ }^{(13)}$. The SI operates using part of the atmospheric steam generated in the PCCS pool and water in a tank on the ground, and injects into the PCCS pool without operator action. This system has some advantages such as earthquake proof, reduction in the PCCS pool volume, and simplification of the upper layout of a nuclear power plant. ${ }^{(13)}$

The conceptual figures of PCCS and SI driven PCCS water refill system are shown in Figs 10 and 11. It consists of a steam line connected to the pressure vessel, heat exchanger tubes, drain line and vent line connected to the suppression pool. The PCCS pool is set on the pressure vessel and its configurations depend on the type of heat exchanger. The water level of the pool is required to cover the heat exchanger tubes at all times through the accident. ${ }^{(13)}$

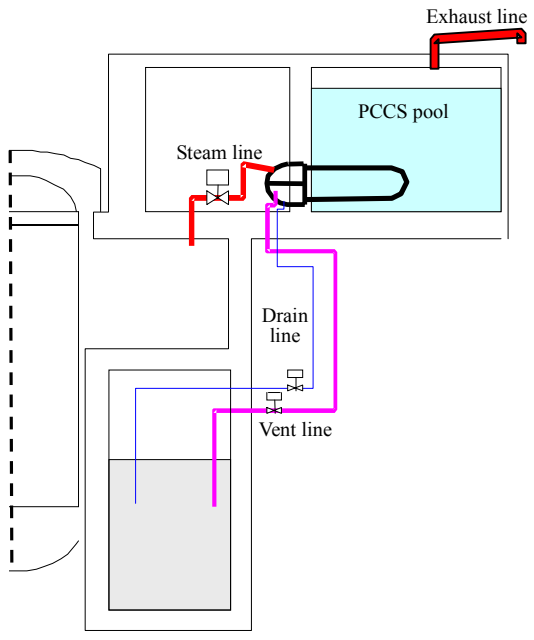

Fig. 10 Conceptual structure of PCCS (Horizontal heat exchanger type)

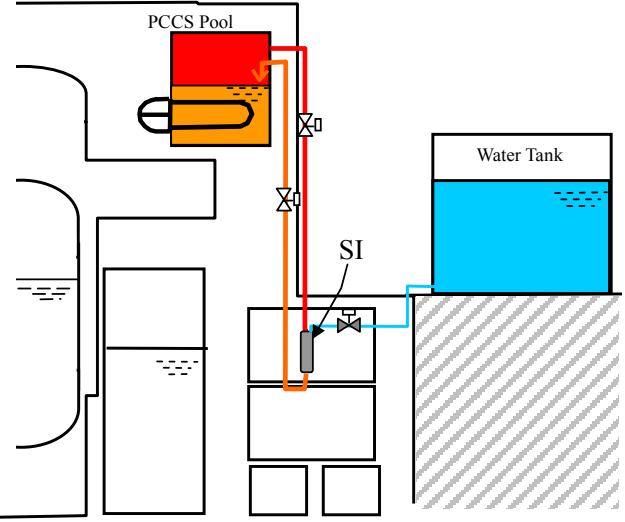

Fig. 11 SI-driven PCCS water refill system

\section{Endurance and Performance Tests of Low-Pressure Steam Injectors}

The performance of a SI doesn't depend on the SI size. The performance of a SI is able to estimated by the theoretical equations calculated with pressure and velocity of steam and water, cross-sectional area-ratio, and so on ${ }^{(14)}$, and confirmed that it shows little scaling-effect by the CFD analysis ${ }^{(7),(8)}$. And the results of analysis by that theoretical 
equation showed good agreement with the test data ${ }^{(15)}$. In addition, the test results of the $1 / 5$-scaled model were almost similar to those of the $1 / 7$-scaled model ${ }^{(16)}$. Therefore, we regard the SI has a geometric-analogy.

The endurance and performance experiments were carried out with scaled models tests to confirm the reliability of SI applied to the actual plants.

\subsection{Endurance Test on Experimental Facility}

The short-term endurance experiment of low-pressure SIs was carried out with very small-scaled model test. In this test, we used steam from the experimental electric boiler.

The test apparatus is shown in Fig.12. The electric boiler, which is an about a-tenth-scaled test vessel representing a RPV, has a $59 \mathrm{~kW}$ heating element to heat water, with a maximum pressure of $1.7 \mathrm{MPa}$ and a maximum temperature of $207^{\circ} \mathrm{C}$. ${ }^{(10)}$ The SI test model is an about $1 / 25$-scaled SI for the low-pressure core injection system.

The test condition is shown in Table 1. Then, Fig.13 shows one of the pressure data in endurance tests.

The SI has undergone a global amount of 44 hours operation during the endurance tests and no performance degradation has been evidenced along the course of experiments. At the same time, a visual inspection of the inner parts of the SI, performed just after the end of the tests, evidenced that relevant erosion phenomena had not occurred in the components.

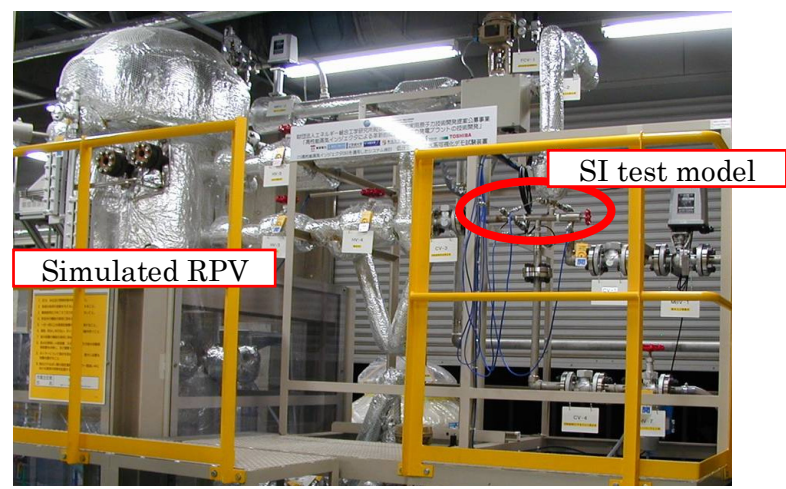

Fig. 12 Endurance test Apparatus in TEPCO R\&D center

Table.1 Endurance test conditions at TEPCO R\&D center

\begin{tabular}{|c|c|c|c|}
\hline Test Parameters & Units & Steam & Water \\
\hline Pressure & $\mathrm{MPa}$ & $0.1-0.2$ & 0.4 \\
\hline Temperature & ${ }^{\circ} \mathrm{C}$ & saturation & 20 \\
\hline Flow rate & $\mathrm{kg} / \mathrm{s}$ & $0.01-0.015$ & 0.12 \\
\hline Discharge pressure & $\mathrm{MPa}$ & - & $0.4-0.75$ \\
\hline
\end{tabular}

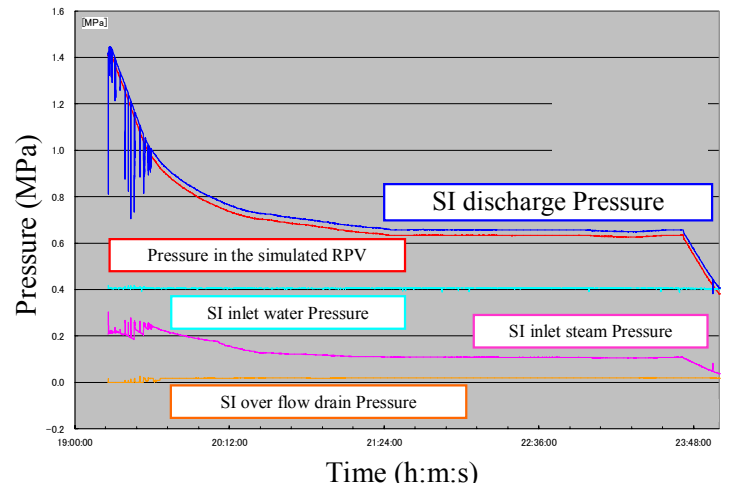

Fig. 13 Pressure data on endurance test

\subsection{Endurance Tests using Actual Steam of Thermal-Power Plant}

The long-term endurance experiments of low-pressure SIs were carried out with a-seventh-scaled models tests. In these tests, we used steam from the actual thermal power 
plant in Republic of Italy. The test apparatus is shown in Fig.14. It was installed in the facilities of SIET S.p.A., shown in Fig.15. The thermal power station of Edipower S.p.A., shown in Fig.16, is in the immediate vicinity. Then a certain number of steams are sent from these thermal power plants to the SIET facilities.

This endurance test was conducted two cases. In both case, the SI test models are a-seventh-scaled SIs for the simplified feed-water heating system.

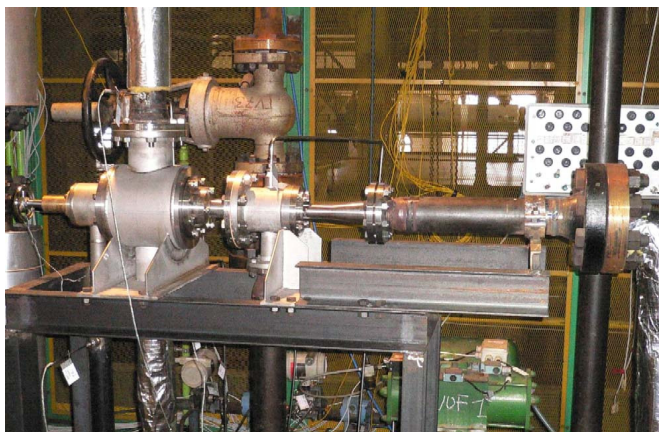

Fig. 14 Endurance test apparatus in SIET (Single-stage SI)

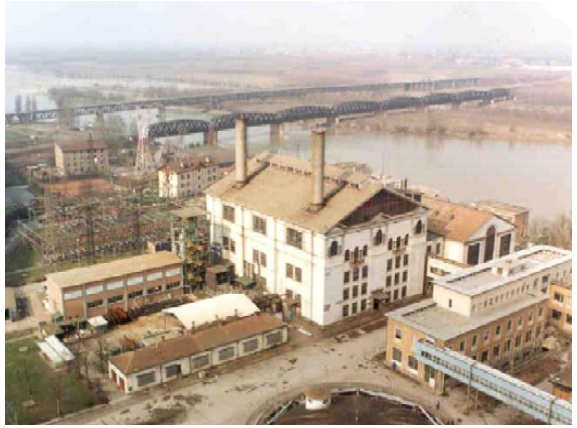

Fig. 15 SIET at Piacenza, Italy

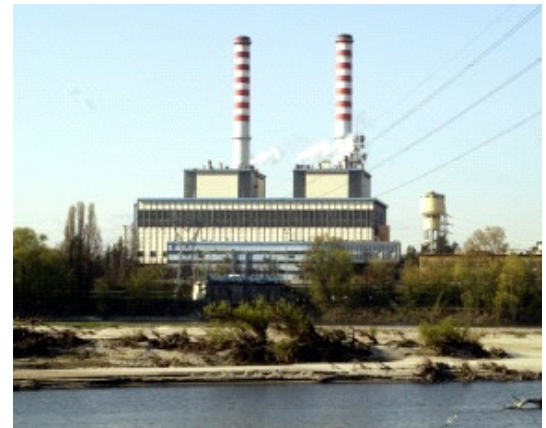

Fig. 16 Thermal power station of Edipower

\subsubsection{Single-stage SI Endurance Test}

The first case, we tested single-stage SI, as shown in Fig.14, for 80 hours operation. In fact, the test was continued for eight hours per day with steady-state conditions and repeated for ten days (discontinuous). Thus, the SI was daily started and stopped for ten days.

The test condition is shown in Table 2. The values described in the table are intended as starting conditions for the daily tests and maintained within the specified ranges. Figure 17 shows one of the pressure data in endurance tests on this case.

Table.2 Endurance test conditions at SIET (Single-stage SI)

\begin{tabular}{|c|c|c|c|}
\hline Test Parameters & Units & Steam & Water \\
\hline Pressure & $\mathrm{MPa}$ & 0.3 & 1.1 \\
\hline Temperature & ${ }^{\circ} \mathrm{C}$ & saturation & $20-64$ \\
\hline Flow rate & $\mathrm{kg} / \mathrm{s}$ & $0.2-0.28$ & $4-4.4$ \\
\hline Discharge pressure & $\mathrm{MPa}$ & - & 0.85 \\
\hline
\end{tabular}

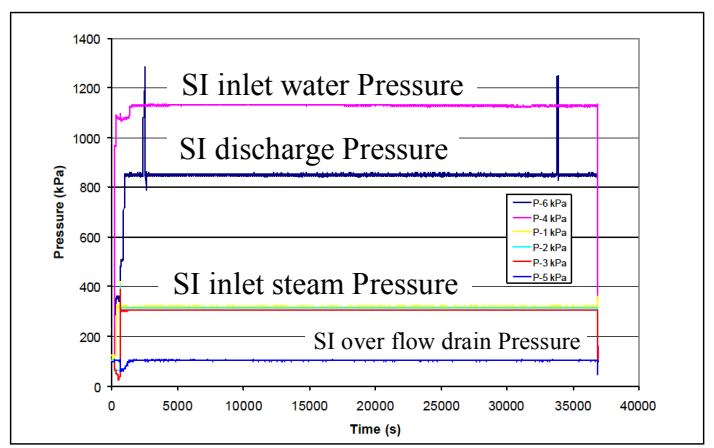

Fig.17 Pressure data on endurance test at SIET (Single-stage SI) 
The SI maximum discharge pressure trend along all endurance tests is shown in Fig.18. The same figure reports also the water inlet temperature and pressure. It is possible to observe that the SI performance remains unvaried along the time and that the maximum pressure values are all included in a quite narrow range going from 1.2 to 1.3 MPa. Only two points are below this range, in correspondence of a water inlet temperature higher than $65{ }^{\circ} \mathrm{C}$.

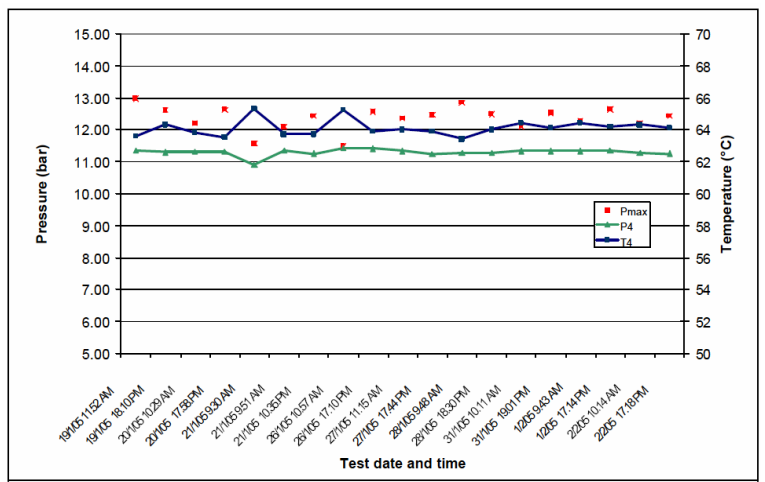

Fig.18 Endurance tests maximum discharge pressure trend

The SI has undergone a global amount of 80 hours operation during the endurance tests and no performance degradation has been evidenced along the course of experiments, by the maximum back pressure tests executed every day in the morning, after the start-up, and in the evening, before the shut down. The SI showed an easy start-up and a very stable operation in the time, once reached the specified test conditions.

Just after the end of the tests, a visual inspection of the inner parts of the SI was performed. Then, we found stitch of vestige of erosion phenomena on the upstream of throat part, as shown in Fig.19. We know that the liquid droplet impingement erosion is occurred in a two-phase flow. The droplets in a two-phase flow impact inner surface of pipe, and the oxide film is removed from the metal surface. The Sanchez equation modeled the wear due to droplet impact in a two-phase flow ${ }^{(17)}$.

The result of surface roughness measurement by microscope, as shown in Fig.20, we verified that the erosion rate is 2 micrometers. Then, we calculated the one-year erosion rate of actual SI. This SI test model is made of SUS304, however the actual SI nozzle will be made of SUS440C. As a broad knowledge in expert of material, the SUS440C has five times endurance for erosion than the SUS304.

$$
2 \mu m \times \frac{10,000 h r}{80 h r} \times \frac{1}{5}=50 \mu m / \text { year }
$$

The amount of erosion wastage is only $1 \mathrm{~mm}$ for 20 years. Thus, low-pressure SI has high endurance characteristic.

This SI endurance test globally showed a good resistance of the component to continuous operation under conditions similar to those for which it is designed.

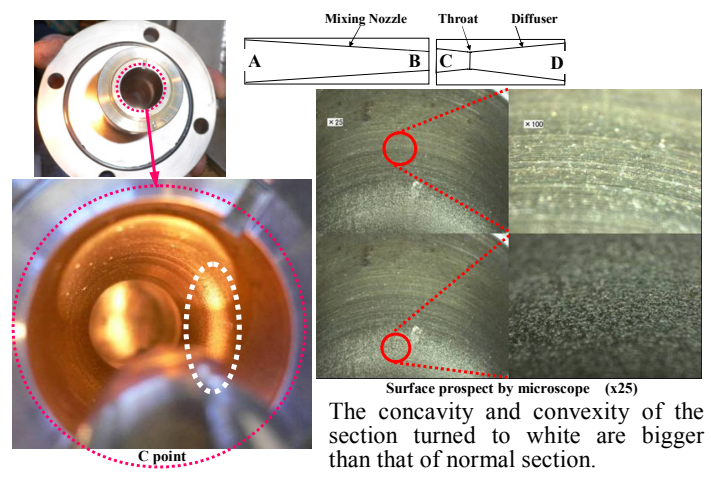

Fig.19 Erosion occurred section

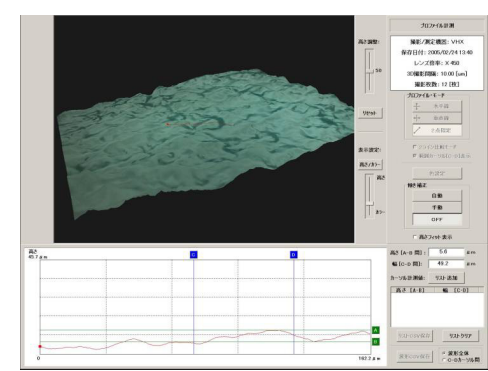

Fig.20 Surface roughness measurement 


\subsubsection{Two-stage SIs Endurance Test}

For the meanwhile, the second case, we tested two-stage SIs, as shown in Fig.21, for 40 hours operation. In fact, the test was continued for eight hours per day with steady-state conditions and repeated for five days (discontinuous). Thus, the SI was daily started and stopped for five days.

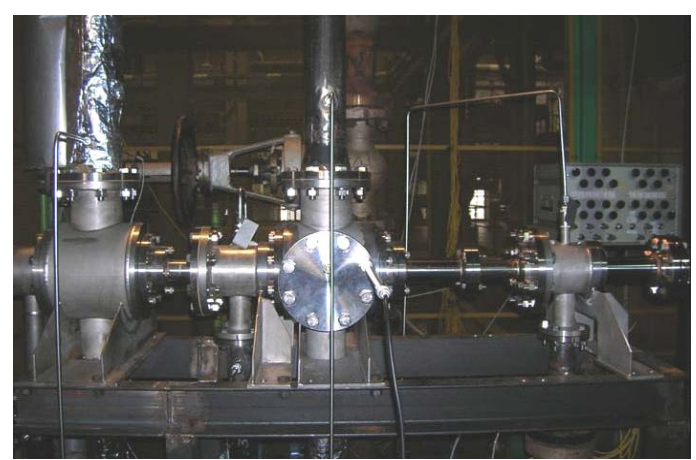

Fig. 21 Endurance test apparatus in SIET (2-stage SIs)

The test condition is shown in Table 3. The values described in the table are intended as starting conditions for the daily tests and maintained within the specified ranges. Figure 22 shows one of the pressure data in endurance tests on this case.

Table.3 Endurance test conditions at SIET (Two-stage SIs)

\begin{tabular}{|c|c|c|c|c|}
\hline Test Parameters & Units & & Steam & Water \\
\hline \multirow{2}{*}{ Pressure } & \multirow{2}{*}{$\mathrm{MPa}$} & $\# 2 \mathrm{SI}$ & $0.1-0.11$ & 1.6 \\
\cline { 3 - 5 } & & $\# 3 \mathrm{SI}$ & 0.2 & - \\
\hline Temperature & ${ }^{\circ} \mathrm{C}$ & $\# 2 \mathrm{SI}$ & saturation & $60-75$ \\
\hline \multirow{2}{*}{ Flow rate } & \multirow{2}{*}{$\mathrm{kg} / \mathrm{s}$} & $\# 2 \mathrm{SI}$ & 0.2 & 4.4 \\
\cline { 3 - 5 } & & $\# 3 \mathrm{SI}$ & 0.2 & - \\
\hline
\end{tabular}

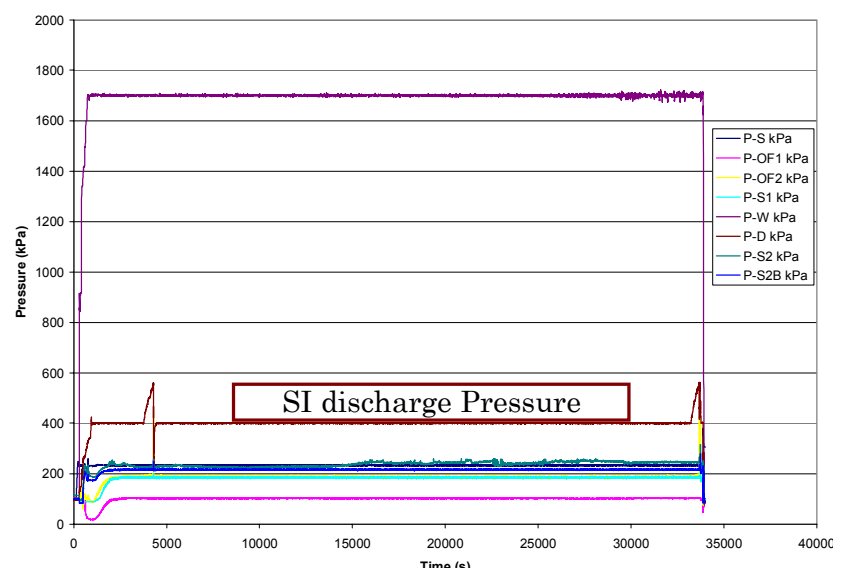

Fig.22 Pressure data on endurance test at SIET (Two-stage SIs)

The SI has undergone a global amount of 43 hours operation during the endurance tests and no performance degradation has been evidenced along the course of experiments, by the maximum back pressure tests executed every day in the morning, after the start-up, and in the evening, before the shut down. The SI showed an easy start-up and a very stable operation in the time, once reached the specified test conditions.

A visual inspection of the inner parts of the SI, performed just after the end of the tests, evidenced that relevant erosion phenomena had not occurred in the components.

This SI endurance test globally showed a good resistance of the component to continuous operation under conditions similar to those for which it is designed.

\subsection{Performance Test of Jet-deaerator}

The performance experiment of SI and Jet-deaerator was carried out with 
a-seventh-scaled models test. In this test, we used steam from the actual thermal power plant in Italy. The test apparatus is shown in Fig.23. This performance test was conducted at SIET along with chapter 3.2.2 endurance tests. In fact, the test was continued for eight hours per day with steady-state conditions and repeated for five days (discontinuous). Thus, the SI and Jet-deaerator were daily started and stopped for five days.

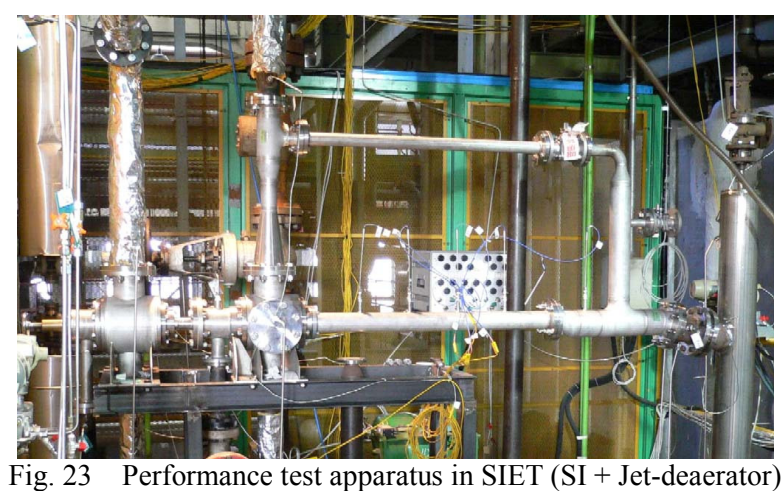

The simplified feed-water heating system with SIs is a direct-contact feed-water heater that heats up feed-water using steam extracted from the low-pressure turbines. Accordingly the system involves the mixing of non-condensable gas produced in the reactor core with low-dissolved oxygen feed-water deaerated in the main steam condenser, and consequently it increases the concentration of dissolved oxygen in the feed-water. To solve this problem, we developed a Jet-deaerater. ${ }^{(2)}$

The upper limit of dissolved oxygen in feed-water is $500 \mathrm{ppb}$, according to studies by the Electric Power Research Institute and some other organizations, but the maximum allowable limit of dissolved oxygen concentration is set at $200 \mathrm{ppb}$ for ABWR plants from the viewpoint of protecting the initial nuclear fuel. Taking into account likely changes in concentration, steps are taken to hold down dissolved oxygen below $100 \mathrm{ppb}$. When the concentration of dissolved oxygen falls below $20 \mathrm{ppb}$, meanwhile, carbon steel loses its oxidized coating which, under this condition, is eluted into a ferrous ion, resulting in the thinning of structural steel members. It is desirable, therefore, that the concentration of dissolved oxygen in feed-water be held in a range from $30 \mathrm{ppb}$ to $100 \mathrm{ppb}$. Large deaeration tanks are often installed at general thermal power plants, but we developed a Jet-deaerator that does not require any large deaeration tank. ${ }^{(2)}$

The test condition is shown in Table 4. The values described in the table are intended as starting conditions for the daily tests and maintained within the specified ranges. Figure 24 shows the dissolved oxygen concentration data of performance test results. The test findings indicate that the Jet-deaerator is capable of reducing the concentration of dissolved oxygen from 1,300 ppb to $50 \mathrm{ppb}$. Thus, the Jet-deaerator can deaerate the feed-water of nuclear power plants to required value.

The SI and Jet-deaerator have undergone a global amount of 44 hours operation during the performance tests and no performance degradation has been evidenced along the course of experiments. The SI and Jet-deaerator showed an easy start-up and a very stable operation in the time, once reached the specified test conditions.

Table.4 Performance test conditions at SIET

\begin{tabular}{|c|c|c|c|c|}
\hline Test Parameters & Units & & Steam & Water \\
\hline \multirow{2}{*}{ Pressure } & \multirow{2}{*}{$\mathrm{MPa}$} & $\mathrm{SI}$ & 0.2 & 1.1 \\
\cline { 3 - 5 } & & Jet DA & 0.4 & - \\
\hline Temperature & ${ }^{\circ} \mathrm{C}$ & $\mathrm{SI}$ & saturation & $75-85$ \\
\hline \multirow{2}{*}{ Flow rate } & \multirow{2}{*}{$\mathrm{kg} / \mathrm{s}$} & $\mathrm{SI}$ & 0.2 & 4.4 \\
\cline { 3 - 5 } & & Jet DA & 0.2 & - \\
\hline
\end{tabular}



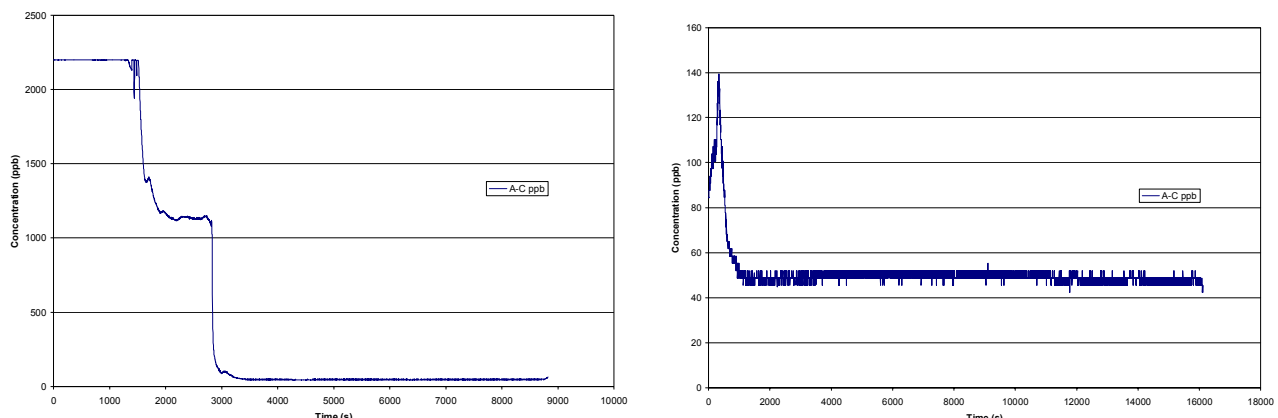

Fig. 24 Dissolved oxygen concentration ratio

\section{Conclusions}

Using high-performance SI system technologies that can be applied for a wider operating range, we have developed on an Innovative-Simplified Nuclear Power Plant design in order to apply the high-performance SIs for the core coolant injection systems and feed-water heating systems.

The endurance and performance tests of low-pressure SIs for feed-water heaters with Jet-deaerator and core injection system were carried out.

The SI has undergone a global amount of 80 hours operation with steam during the endurance tests and no performance degradation has been evidenced along the course of experiments, by the maximum back pressure tests executed every day in the morning, after the start-up, and in the evening, before the shut down. The SI showed an easy start-up and a very stable operation in the time, once reached the specified test conditions. Consequently a visual inspection of the inner parts of SI, we found stitch of vestige of erosion phenomena on the upstream of throat part. But the result of in-depth estimation, we verified that the low-pressure SIs have high endurance characteristic.

These SI endurance and performance tests globally showed a good resistance of the component to continuous operation under conditions similar to those for which it is designed

It was confirmed that the low-pressure SIs have adequate reliability, which is endurance and performance, to apply to feed-water heaters with Jet deaerator and core injection system of the actual power plants.

\section{Acknowledgements}

A part of this paper are fruits of research which is carried out by TEPCO, Toshiba, and 7 Universities in Japan, funded from the Ministry of Economy, Trade and Industry (METI) of Japan as the national public research-funded program.

The authors would like to thank to professors Yabe of Tokyo Institute of Technology, Koizumi of Kogakuin University, Kataoka of Osaka University, Okamoto of The University of Tokyo, Abe of University of Tsukuba, Tanaka of Ibaragi University, and Sugiyama of Hokkaido University for their cooperative efforts to initiate the project and coming collaboration in the joint research.

\section{References}

(1) Narabayashi T. et al., Analytical Study on Large Scale Steam Injector to Next-Generation BWR, Proceedings of the 3rd International Conference on Nuclear Engineering (ICONE-3), (1994), pp.877-883

(2) Ohmori S. et al., Development of Steam Injector Feedwater Heater System, Proceedings of the 7th International Conference on Nuclear Engineering (ICONE-7), (1999-4), pp.233, ICONE-7371 
(3) Narabayashi T. et al., Development of Steam Injector Feedwater Heater System, Proceedings of the 8th International Conference on Nuclear Engineering (ICONE-8), (2000-4), ICONE-8582

(4) Ohmori S. et al., Simplified Feedwater Heater System by Multi-Stage Steam Injectors, Proceedings of 2nd Japan-Korea Symposium on Nuclear Thermal Hydraulics and Safety (NTHAS2), (2000-10), pp.351-355

(5) Mori M. et al., Development of Simplified Steam Injector Feedwater Heater System -Large Scale Model Tests and Design Improvement by CFD-, Proceedings of the 11th International Conference on Nuclear Engineering (ICONE-11), (2003), pp.312, ICONE11-36488

(6) Mori M. et al., Research and Development Program of Innovative Simplified and Severe-Accident-Free BWR by High-Performance Steam Injector System, Proceedings of the 2003 International Congress on Advances in Nuclear Power Plants (ICAPP'03), (2003), Paper 3294

(7) Narabayashi T. et al., Study on Two-Phase Flow Dynamics in Steam Injectors, Nuclear Engineering and Design, Vol.175 (1997), pp.147-156.

(8) Narabayashi T. et al., Study on Two-Phase Flow Dynamics in Steam Injectors, II. High-Pressure tests using Scale-Models, Nuclear Engineering and Design, Vol.200 (2000), pp.261-271.

(9) Ohmori S. et al., Development of Technologies on Innovative-Simplified Nuclear Power Plant using High-Efficiency Steam Injectors -(1) Investigation to keep the covered Core Water Level by SI Core Coolant Passive Injection System-, Proceedings of 4th Japan-Korea Symposium on Nuclear Thermal Hydraulics and Safety (NTHAS4), (2004-11), pp.519-521

(10) Ohmori S. et al., Development of Technologies on Innovative-Simplified Nuclear Power Plant using High-Efficiency Steam Injectors (1) Demonstration test of SI Core Coolant Passive Injection System, Proceedings of the 13th International Conference on Nuclear Engineering (ICONE-13), (2005-5), pp.461, ICONE13-50650

(11) Goto S. et al., Innovative-Simplified Nuclear Power Plant Efficiency Evaluation with High-Efficiency Steam Injector System, Proceedings of the 2006 International Congress on Advances in Nuclear Power Plants (ICAPP'06), (2006-6), pp.1-6, Paper 6466

(12) Yokobori S. et al., System response test of isolation condenser applied as a passive containment cooling system, Proceedings of the 1st International Conference on Nuclear Engineering (ICONE-1), (1991), pp.265-271

(13) Iwaki C. et al., Development of Technologies on Innovative-Simplified Nuclear Power Plant using High-Efficiency Steam Injectors (4) Air-Purge Analysis for Water Makeup System, Proceedings of the 13th International Conference on Nuclear Engineering (ICONE-13), (2005-5), pp.482, ICONE13-50625

(14) Narabayashi T. et al., Study on High-Performance Steam Injector (1st Report, Development of Analytical Model for Characteristic Evaluation), Transactions of the Japan Society of Mechanical Engineers, Series B, Vol.62, No.597, (1996), pp.1833-1840. (in Japanese)

(15) Iwaki C. et al., Study on High-Performance Steam Injector (2nd Report, Measurement of Jet Structure), Transactions of the Japan Society of Mechanical Engineers, Series B, Vol.69, No.684 (2003), pp.1814-1821. (in Japanese)

(16) Narabayashi T. et al., Development of Multi-Stage Steam Injector for Feedwater Heaters in Simplified Nuclear Power Plant, JSME International Journal, Series B, Vol.49, No.2 (2006), pp.368-376.

(17) R. G. Keck, P. Griffith, Prediction and Mitigation of Erosive-Corrosive Wear in Secondary Piping Systems of Nuclear Power Plants, NUREG/CR-5007 R5, (1987) 